\title{
SISTEM PEMBUKAAN KUNCI AUTOMATIS MENGGUNAKAN IDENTIFIKASI POLA KETUKAN
}

\author{
Alan Prasetyo R. ${ }^{1)}$, R. Rizal Isnanto ${ }^{2)}$, Eko Didik Widianto ${ }^{2)}$ \\ Program Studi Sistem Komputer, Fakultas Teknik, Universitas Diponegoro \\ Jalan Prof. Sudharto, Tembalang, Semarang, Indonesia
}

\begin{abstract}
During this time automatic unlocking still use the physical tools as the authentication method, which potentially damaged or lost. Authentication method of automatic unlocking system does not use technology which allows unique information to be stored without the need for physical tools and where everyone can use it. Therefore, research needs to be done to develop an automatic unlocking system using knocking pattern identification as the authentication method.

System consists of hardware and software. Hardware consist of sensor which are buzzer, ATTiny85 as microcontroller and solenoid lock as actuator. Software is coded using $C$ language with Arduino IDE which is compatible with AVR microcontroler. The system can read the knocking pattern from buzzer then identify it as true or false knock.

From the test results, system can identify knocking pattern based on number of knocks, time beetween knocks and soft or loud of knocks. The system identifies the knocking patterns by analyzing its pattern compared with the true knock saved in system memory. Knocking pattern identification can be an alternative of authentication system for automatic unlocking system.
\end{abstract}

Keywords: Security method, Knocking Pattern, Arduino, Automatic Unlocking System

\section{PENDAHULUAN}

Sebagai suatu disiplin ilmu, rekayasa teknik dalam teknologi keamanan bertujuan untuk digunakan dalam pengembangan dan/atau penyempurnaan suatu sistem keamanan. Salah satu contoh sistem keamanan yang berkembang yakni sistem pembukaan kunci, yang umumnya ditemukan pada pintu, lemari hingga kotak deposit. Sistem pembukaan kunci mulai secara elektronik maupun mekanik telah banyak dipergunakan, menggunakan data yang disimpan dalam kartu atau alat fisik lainnya hingga menggunakan berbagai sistem pembukaan kunci mekanis yang dikombinasikan dengan sistem elektronik. Selama ini sistem keamanan pembukaan kunci automatis umumnya menggunakan alat autentikasi fisik ${ }^{[1]}$. Oleh sebab itu, diperlukan sistem pengamanan pembukaan kunci otomatis menggunakan metode baru yang diharapkan menjadi alternatif solusi sistem pembukaan kunci automatis konvensional. Salah satunya dengan menggunakan metode identifikasi pola ketukan sebagai metode autentikasi pada sistem pembukaan kunci automatis. Sistem keamanan pembukaan kunci automatis menggunakan pola ketukan adalah konsep autentikasi yang tidak membutuhkan alat fisik. Ke- tukan akan digunakan sebagai informasi autentikasi kunci yang akan mengaktifkan suatu sistem pembukaan kunci apakah aktif atau tidak. Kombinasi ketukan akan menghasilkan jarak waktu antar tiap ketukan sehingga menghasilkan suatu ritme, jarak waktu inilah yang akan dianalisis oleh sistem untuk melakukan aktifasi sistem pembukaan kunci. Ritme ketukan yang diterima akan disimpan oleh sistem hanya dalam bentuk pewaktuan. Selain penggunaan ritme ketukan, autentikasi juga mengidentifikasi jumlah ketukan dan pelan atau kerasnya ketukan. Sistem keamanan pembukaan kunci automatis menggunakan pola ketukan dapat memberikan alternatif metode autentikasi dalam sistem pembukaan kunci automatis.

\subsection{Rumusan Masalah}

Berdasarkan latar belakang yang telah dijelaskan di atas, dapat dibuat rumusan masalah sebagai berikut:

1. Bagaimana merancang alternatif sistem pembukaan kunci automatis yang diaktifkan oleh kombinasi unik pola ketukan?

2. Bagaimana membuat sistem mampu mengenali kombinasi pola ketukan untuk proses aktivasi sistem pembukaan kunci?

\subsection{Batasan Masalah} Untuk menghindari pembahasan yang meluas, maka dalam Tugas Akhir ini ditetapkan batasan-batasan masalah sebagai berikut.

1. Sistem bertugas untuk membuka kunci secara automatis dengan mengidentifikasi pola ketukan.

2. Pola ketukan yang dimaksud adalah jumlah ketukan (maksimal 10 ketukan), jarak waktu antar ketukan dan pelan atau kerasnya ketukan.

3. Sistem bekerja menggunakan perangkat Adafruit Trinket sebagai papan pengembangan mikrokontrolernya dan menggunakan Piezo Buzzer sebagai perangkat masukannya, yang dirancang dan dirangkaikan dengan instrumen elektronik lainnya dalam satu papan rangkaian elektronik.

4. Lingkup kerja sistem adalah pada metode kontrol akses sistem pembukaan kunci automatis yang diaktifkan oleh pola ketukan dan menggunakan kunci solenoid sebagai aktuatornya. Penelitian tidak berfokus pada pembuatan sistem pengamanan yang handal namun pada alternatif metode kontrol akses yang kemudian dapat dikembangkan dalam rekayasa teknik pengamanan.

5. Keseluruhan sistem ini bersifat purwarupa tetapi memungkinkan masih adanya bug. 
6. Sistem hanya diperuntukkan untuk mengenali pola ketukan sebagai autentikasi sistem pembukaan kunci, ketukan dapat diganti dengan ketukan yang baru.

7. Ritme ketukan akan disimpan oleh sistem hanya dalam bentuk pewaktuan, yakni jarak waktu antar tiap ketukan dalam satu rangkaian kombinasi ketukan. Sehingga sekalipun melakukan ketukan dalam waktu yang lebih lambat ataupun cepat sistem tetap dapat mengenali ketukan tersebut selama memiliki perbandingan jarak waktu ketukan yang relatif sama dengan data waktu yang disimpan oleh sistem, jarak ketukan yang relatif sama berarti tidak melebihi nilai toleransi yang ditentukan.

\subsection{Tujuan Penelitian}

Adapun tujuan penelitian yang akan dicapai adalah sebagai berikut.

1. Sistem pembukaan kunci automatis mampu dikendalikan oleh kombinasi pola ketukan sebagai alternatif metode kontrol akses.

2. Sistem dapat mengenali dan merespon dengan benar masukan kombinasi pola ketukan yang diterimanya.

3. Sistem dapat dikonfigurasi agar bisa menerima masukan kombinasi pola ketukan yang baru, yakni mengganti pola ketukan yang disimpan sistem.

\section{DASAR TEORI}

Penelitian yang akan dilakukan berlandaskan pada berbagai teori yang memungkinkan tujuan penelitian dapat tercapai. Teori-teori tersebut menjadi dasar yang membangun penelitian dengan memberikan definisi dan penjabaran yang diperlukan dalam pelaksanaan penelitian, berikut Landasan Teori tersebut.

\subsection{Kunci}

Kunci adalah perangkat mekanik atau elektrik yang dikendalikan oleh suatu objek fisik (seperti kunci, kartu, sidik jari, kartu radio-frequency identification atau token keamanan) yang berisi informasi rahasia. Kunci umumnya digunakan untuk memungkinkan seseorang mengakses sesuatu yang dilindungi dalam tempat tertentu. Sistem penguncian pertama ditemukan pada reruntuhan Nineveh, ibukota dari Assyria kuno. Kemudian berkembang ke kunci pin kayu di Mesir, yang terdiri atas baut, pintu dan kunci. Ketika kunci dimasukkan, pin diantara pintu terangkat dari lubang diantara baut yang memungkinkannya untuk bergerak. Ketika kunci dilepas, pin terlepas kedalam baut yang mencegah pergerakan, seperti terlihat pada Gambar 1.

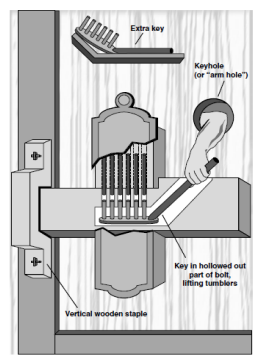

Gambar 1 Kunci Pin Kayu Mesir Kuno ${ }^{[5]}$
Banyak sistem pembukaan kunci yang menggunakan proses mekanik yang rumit hingga menggunakan sistem elektrik. Selain metode pembukaan kunci automatis yang rumit, metode untuk melakukan validasi pembukaan kunci juga semakin rumit, banyak yang bahkan sudah menggunakan informasi-informasi biometrik yang unik seperti informasi bentuk iris mata, sidik jari hingga bentuk wajah seseorang dijadikan untuk melakukan proses autentikasi dalam sistem penguncian. Selain penggunaan informasi penguncian menggunakan informasi biometrik juga menggunakan kartu identitas sebagai alat autentikasi hingga menggunakan metode lama seperti bentuk-bentuk kunci konvensional. Sistem pembukaan kunci umumnya banyak ditemukan pada pintu, hingga menggunakan sistem alarm untuk mencegah pembukaan paksa suatu pintu. ${ }^{[5]}$

\subsection{Adafruit Trinket}

Adafruit Trinket adalah papan sirkuit mikrokontroler yang menggunakan Atmel ATtiny85. Papan sirkuit ini didesain sedemikian rupa sehingga memberikan ukuran papan sirkuit yang relatif kecil untuk dapat digunakan pada berbagai macam pengembangan. Arduino Trinket telah dilengkapi dengan USB Bootloader sehingga dapat diprogram seperti perangkat papan sirkuit Arduino pada umumnya. Gambar 2 menunjukkan wujud dari Adafruit Trinket $^{[4]}$.

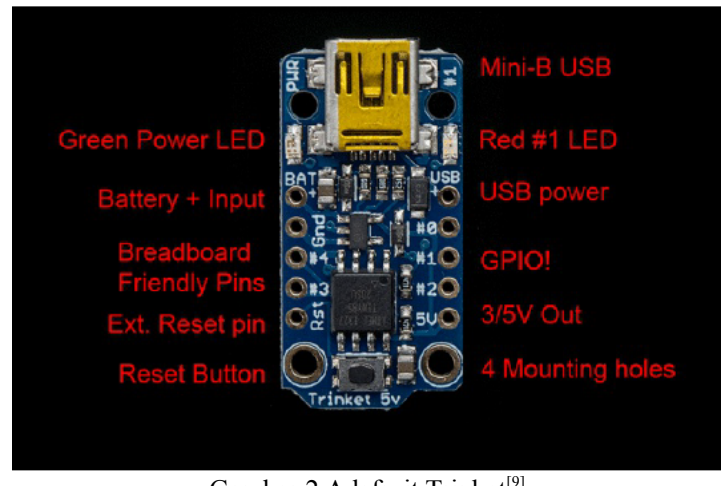

Gambar 2 Adafruit Trinket ${ }^{[9]}$

2.3 Pemrograman pada mikrokontroler AVR dan Arduino

Alur pemrograman pada mikrokontroler AVR tidak jauh berbeda dengan melakukan pemrograman mikrokontroler pada umumnya. Dimulai dari membuat kode sumber pada editor, mengubah kode sumber ke kode mesin menggunakan compiler, menggunakan perangkat lunak pengunggah dan perangkat flash programmer dan mengirim kode mesin tersebut ke chip AVR yang akan menyimpan instruksi tersebut ke memori flash nonvolatile yang dimilikinya ${ }^{[2]}$.

\section{PERANCANGAN SISTEM}

Pada bagian ini akan dijabarkan mengenai kebutuhan dan metode yang digunakan untuk merancang perangkat keras dan perangkat lunak sistem. Perancangan diperlukan untuk memberikan metode dan tahapan yang jelas untuk membuat sistem sesuai dengan tujuan yang telah ditentukan. 
3.1 Identifikasi Kebutuhan Sistem

Proses ini dibutuhkan untuk melakukan proses identifikasi dan proses analisa kebutuhan-kebutuhan yang diperlukan untuk membuat sistem. Kebutuhan-kebutuhan tersebut terdiri atas kebutuhan fungsional dan non-fungsional, yang dijelaskan sebagai berikut.

\subsubsection{Kebutuhan Fungsional}

Kebutuhan fungsional dalam perancangan sistem adalah sebagai berikut:

a. Sistem mengenali pola ketukan yakni jumlah ketukan, jarak waktu antar ketukan dan keras atau pelannya ketukan yang akan dibandingkan dengan pola ketukan yang disimpan sistem. Untuk membedakan ketukan lemah dan keras maka diberikan nilai ambang batas ketukan lemah dan keras. Ketukan lemah berada pada nilai analog 3-100 sedangkan ketukan keras dari 101-1023.

b. Adanya fasilitas untuk mengubah pola ketukan yang telah tersimpan dalam sistem kemudian memasukkan pola ketukan yang baru dengan menggunakan tombol tekan untuk mengaktifkan mode tersebut.

c. Kondisi dan perilaku sistem dikenali dengan mengaktifkan LED (Light Emitting Diode) dan mengeluarkan suara melalui buzzer, hal ini untuk memudahkan pengguna mengetahui kondisi atau status sistem saat itu.

\subsubsection{Kebutuhan Non-Fungsional}

Kebutuhan non-fungsional perancangan sistem adalah sebagai berikut:

a. Purwarupa sistem dibuat sedemikian rupa sehingga memudahkan dalam proses pemasangan dan penggunaannya.

b. Untuk pelan dan kerasnya ketukan diasumsikan bahwa ketukan pelan adalah ketukan yang dianggap pengguna adalah ketukan pelan dan ketukan keras adalah ketukan yang membutuhkan tenaga yang lebih dibandingkan ketukan pelan.

c. Buzzer harus diletakkan sedekat mungkin dengan bidang ketukan, karena getaran dari material bidang ketukanlah yang akan dibaca oleh sistem.

\subsection{Perancangan Perangkat Keras}

Proses perancangan perangkat keras akan menjabarkan rancangan perangkat keras yang akan digunakan untuk membuat sistem, mulai dari perangkat keras utama yang dibutuhkan sistem hingga instrumen-instrumen elektronika pendukungnya. Pada Gambar 3 ditunjukkan diagram blok perangkat keras sistem, yang menunjukkan rancangan perangkat keras sistem yang akan dibuat.

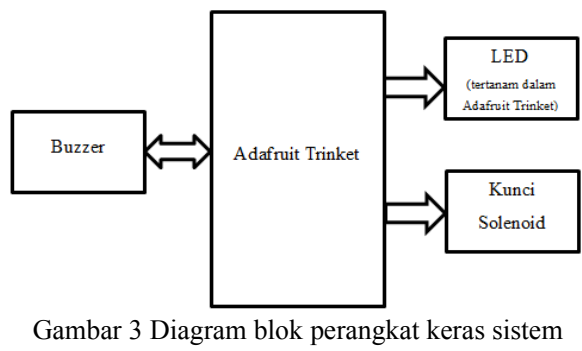

Perancangan papan sirkuit elektronik dibutuhkan untuk menghubungkan komponen-komponen elektronika yang dibutuhkan untuk membuat purwarupa sistem ${ }^{[3]}$.

Papan sirkuit elektronik terlebih dahulu dirancang menggunakan perangkat lunak. Pad2Pad dipilih sebagai perangkat lunak untuk merancang papan sirkuit elektronik sistem. Papan sirkuit elektronik memiliki ukuran 63,96 x 38,07 mm. Gambar 4 menunjukkan rancangan papan sirkuit elektronik yang dibuat menggunakan perangkat lunak Pad2Pad.

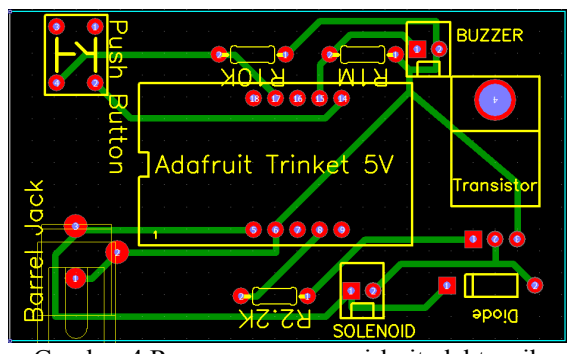

Gambar 4 Rancangan papan sirkuit elektronik

\subsection{Perancangan Perangkat Lunak}

Perancangan perangkat lunak digunakan untuk memberikan tahapan yang jelas dalam pembuatan program yang akan mengendalikan perangkat keras dan menjadi otak yang mengidentifikasi dan menilai ketukan yang diterima sistem terhadap pola ketukan yang dsimpan sistem. Sistem harus mampu mengenali ketukan dengan berpatokan pada dua variabel yakni nilai ritme atau jarak waktu antar ketukan dan keras atau pelannya ketukan yang diterima sistem. Pada bagan alir yang disajikan pada Gambar 5 ditunjukkan mengenai rancangan perilaku sistem yang akan dibuat.

Sistem terlebih dahulu menilai ketukan yang diterimanya apakah lebih atau sama dengan nilai ambang batas yang dimilikinya, jika nilai ketukan yang diterima sama atau melebihi nilai batas yang telah ditentukan maka ketukan tersebut akan mengaktifkan fungsi-fungsi perangkat lunak laiinnya dalam program. Ketukan yang diterima sistem akan dinilai terhadap tiga hal, yakni jumlah ketukan, nilai jarak waktu antar ketukan (waktu diam antar tiap ketukan) dan nilai keras dan pelannya ketukan yang diterima oleh sistem dalam nilai analog $(0$ 1023), namun nilai analog ini harus dibuktikan agar nilai batas keras dan nilai batas pelan ketukan diketahui dan dijadikan patokan nilai dalam sistem yang akan dikembangkan seperti yang dijelaskan pada kebutuhan fungsional.

Perangkat lunak akan dibuat menggunakan lingkungan pengembangan Arduino IDE dengan bahasa pemrograman yang mirip dengan bahasa C. Perangkat lunak tersebut akan terdiri atas beberapa fungsi seperti yang ditunjukkan pada Tabel 1 .

Tabel 1 Fungsi-fungsi pada perangkat lunak sistem.

\begin{tabular}{|l|l|l|}
\hline No. & \multicolumn{1}{|c|}{ Fungsi } & \multicolumn{1}{c|}{ Keterangan } \\
\hline 1. & setup & Inisialisasi sistem. \\
\hline 2. & loop & $\begin{array}{l}\text { Mengenali ketukan paling pertama dan } \\
\text { mengaktifkan fungsi-fungsi berikutnya. } \\
\text { Termasuk ketika tombol tekan aktif }\end{array}$ \\
\hline 3. & $\begin{array}{l}\text { Dengar- } \\
\text { Ketukan }\end{array}$ & $\begin{array}{l}\text { Mengenali jarak waktu dan keras atau } \\
\text { pelannya ketukan. }\end{array}$ \\
\hline
\end{tabular}




\begin{tabular}{|l|l|l|}
\hline 4. & bukaKunci & Mengaktifkan kunci solenoid. \\
\hline 5. & $\begin{array}{l}\text { Validasi- } \\
\text { Ketukan }\end{array}$ & $\begin{array}{l}\text { Melakukan proses analisa ketukan } \\
\text { terhadap pola ketukan yang disimpan } \\
\text { sistem. }\end{array}$ \\
\hline 6. & $\begin{array}{l}\text { Baca- } \\
\text { Ketukan- } \\
\text { Rahasia }\end{array}$ & $\begin{array}{l}\text { Membaca ketukan yang disimpan dalam } \\
\text { EEPROM pada saat sistem pertama kali } \\
\text { diaktifkan. }\end{array}$ \\
\hline 7. & $\begin{array}{l}\text { Simpan- } \\
\text { Ketukan- } \\
\text { Rahasia }\end{array}$ & $\begin{array}{l}\text { Menyimpan pola ketukan yang baru ke } \\
\text { EEPROM. }\end{array}$ \\
\hline 8. & $\begin{array}{l}\text { Mainkan- } \\
\text { Kembali- } \\
\text { Ketukan }\end{array}$ & $\begin{array}{l}\text { Mengeluarkan bunyi melalui buzzer yang } \\
\text { menunjukkan ketukan baru yang disimpan } \\
\text { sistem. }\end{array}$ \\
\hline 9. & $\begin{array}{l}\text { Baca- } \\
\text { Amplitudo }\end{array}$ & $\begin{array}{l}\text { Mengenali keras dan pelannya ketukan. } \\
\text { chirp }\end{array}$ \\
\hline 10. & $\begin{array}{l}\text { Mengeluarkan bunyi saat tombol tekan } \\
\text { aktif dan sistem siap menerima ketukan } \\
\text { yang baru. }\end{array}$ \\
\hline
\end{tabular}

keseluruhan pada kotak purwarupa. Hasil implementasi perangkat keras disajikan pada Gambar 6 setelah komponen dipasang dan Gambar 7 setelah keseluruhan sistem menjadi sebuah perangkat keras purwarupa.
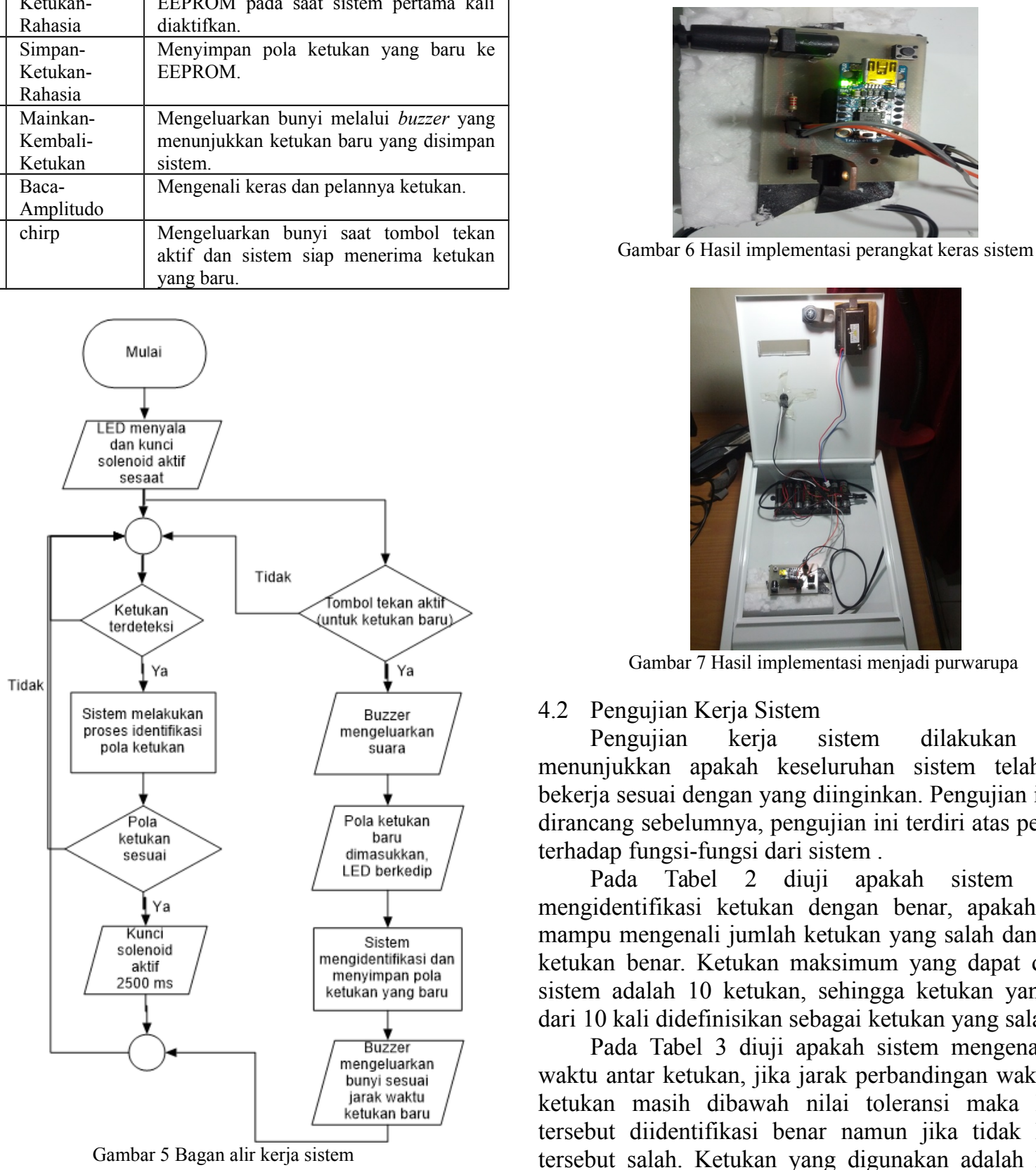

Gambar 7 Hasil implementasi menjadi purwarupa

\subsection{Pengujian Kerja Sistem}

Pengujian kerja sistem dilakukan untuk menunjukkan apakah keseluruhan sistem telah dapat bekerja sesuai dengan yang diinginkan. Pengujian ini telah dirancang sebelumnya, pengujian ini terdiri atas pengujian terhadap fungsi-fungsi dari sistem .

Pada Tabel 2 diuji apakah sistem mampu mengidentifikasi ketukan dengan benar, apakah sistem mampu mengenali jumlah ketukan yang salah dan jumlah ketukan benar. Ketukan maksimum yang dapat diterima sistem adalah 10 ketukan, sehingga ketukan yang lebih dari 10 kali didefinisikan sebagai ketukan yang salah.

Pada Tabel 3 diuji apakah sistem mengenali jarak waktu antar ketukan, jika jarak perbandingan waktu antar ketukan masih dibawah nilai toleransi maka ketukan tersebut diidentifikasi benar namun jika tidak ketukan tersebut salah. Ketukan yang digunakan adalah ketukan sebanyak 4 (empat) kali, ketukan tersebut divisualisasikan seperti yang ditunjukkan pada Gambar 8. Ketukan divisualisasikan dalam rasio waktu antar ketukan, dimana rasio pada gambar adalah rasio jarak waktu normal pada saat pengujian.

Tabel 2 Hasil pengujian identifikasi jumlah ketukan

\begin{tabular}{|l|l|l|}
\hline No. & Jumlah ketukan & Keterangan \\
\hline 1. & $\begin{array}{l}\text { Jumlah ketukan kurang dari atau } \\
\text { sama dengan 10 }\end{array}$ & Benar \\
\hline 2. & Jumlah ketukan lebih dari 10 & Salah \\
\hline
\end{tabular}
yang telah dibuat dan mampu memberikan hasil pengolahan masukan dengan benar serta memberikan perilaku-perilaku serta keluaran sesuai kebutuhan.

\footnotetext{
4.1 Implementasi Perangkat Keras dan Perangkat Lunak

Perangkat keras sistem yang telah dirancang sebelumnya akan diimplementasikan, mulai dari pembuatan sistem hingga pemasangan perangkat sistem
} 


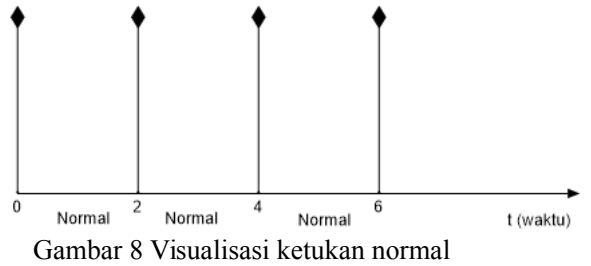

Hasil pengujian identifikasi rasio waktu antar ketukan disajikan dalam bentuk visualisasi pewaktuan antar ketukan yang dinormalisasikan. Jarak waktu antar ketukan normal akan diidentifikasi sebagai ketukan yang benar, namun apabila salah satu ketukan atau kurang dari 4 ketukan, cepat atau lambat terhadap waktu normal maka ketukan tersebut diidentifikasi sebagai ketukan yang salah. Keseluruhan ketukan yang lambat atau cepat terhadap waktu normal akan diidentifikasi sebagai ketukan yang benar, selama rasio perbandingan waktu antar ketukan masih sama. Namun ketukan yang terlalu lambat atau terlalu cepat terhadap waktu normal akan diidentifikasikan sebagai ketukan yang salah karena dalam sistem telah dibuat batas waktu toleransi antar ketukan, sehingga apabila jarak waktu antar ketukan lebih dari nilai batas toleransi waktu antar ketukan dalam sistem, maka ketukan tersebut adalah ketukan yang salah. Ketukan terlalu cepat akan memberikan nilai negatif, namun sistem memberikan nilai mutlak, sehingga perbedaan waktu lebih dari 25 milidetik adalah ketukan yang salah. Pada Gambar 9 disajikan visualisasi penggunaan nilai toleransi untuk menentukan ketukan terlalu lambat atau terlalu cepat. Hasil pengujian disajikan pada Tabel 3.
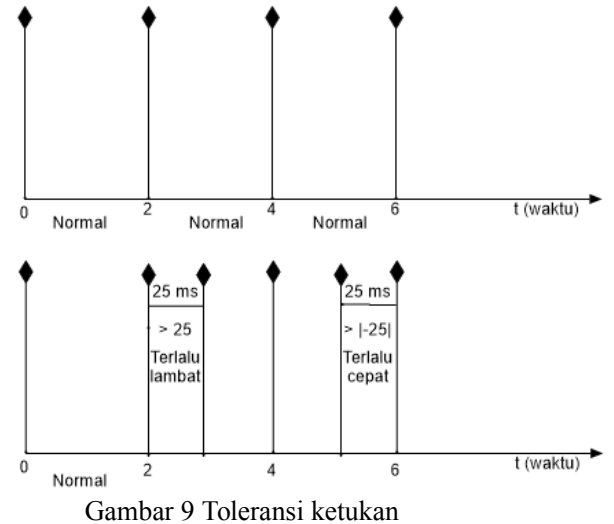

Tabel 3 Hasil pengujian identifikasi jarak waktu antar ketukan

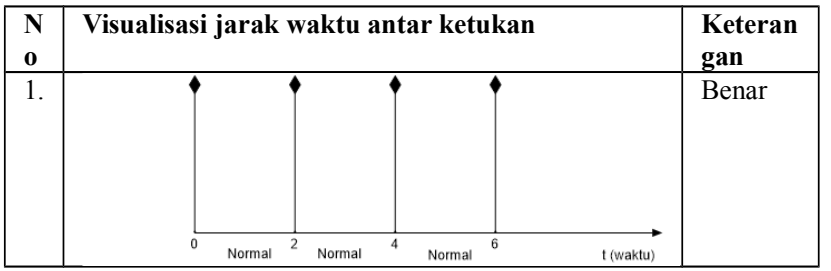

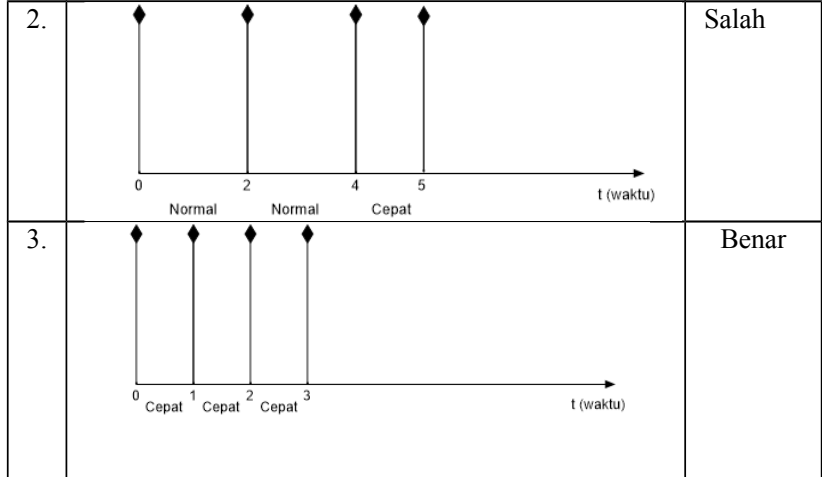

Pada Tabel 4 diuji apakah sistem mampu mengenali pelan atau kerasnya ketukan. Ketukan yang diuji adalah ketukan yang disimpan dalam EEPROM pada saat pertama kali diaktifkan yakni ketukan pelan sebanyak dua kali dengan jarak waktu 50 milidetik. Dengan demikian pengujian dilakukan dengan kombinasi dua buah ketukan sebanyak empat kombinasi.

Tabel 4 Hasil pengujian identifikasi pelan atau kerasnya ketukan

\begin{tabular}{|l|l|l|}
\hline No. & Kombinasi ketukan & Keterangan \\
\hline 1. & Keras-Keras & Salah \\
\hline 2. & Keras-Pelan & Salah \\
\hline 3. & Pelan-Keras & Salah \\
\hline 4. & Pelan-Pelan & Benar \\
\hline
\end{tabular}

Berdasarkan hasil pengujian pada Tabel 4, ditunjukkan bahwa sistem mampu mengenali pelan atau kerasnya ketukan, ketukan yang benar adalah ketukan pelan sebanyak dua kali sehingga ketukan dengan pola ketukan yang berbeda akan didefinisikan sebagai ketukan yang salah.

\subsection{Skenario Pengujian Pertama}

Skenario pengujian pertama dilakukan dengan melakukan ketukan langsung pada permukaan buzzer dan tidak pada permukaan kotak purwarupa, seperti yang ditunjukkan pada Gambar 4.8. Dalam pengujian ini diberikan ketukan pada permukaan buzzer menggunakan jari, pemberian ketukan tanpa melalui material bidang permukaan yang kemudian diteruskan ke buzzer memungkinkan suara yang dihasilkan pada saat memberikan ketukan dapat diminimalkan. Hasil pengujian menunjukkan sistem tetap dapat mengenali ketukan yang diberikan sekalipun langsung mengetuk pada permukaan buzzer, namun pengguna harus memantau kedipan LED merah agar dapat memastikan sistem menerimanya sebagai ketukan.

\subsection{Skenario Pengujian Kedua}

Skenario pengujian kedua berupa pengujian dengan menggunakan alat perekam untuk menunjukkan apakah sistem dapat mengenali ketukan yang direkam. Dalam pengujian ini dimasukkan ketukan baru ke sistem dan pada saat memasukkan ketukan baru, ponsel pintar diaktifkan untuk merekam ketukan tersebut. Hasil rekaman tersebut dimainkan kembali dekat dengan kotak purwarupa. Setelah melakukan pengujian, maka didapatkan hasil bahwa sistem tidak mampu mengenali ketukan yang direkam pada ponsel pintar, bahkan rekaman 
tersebut tidak terdeteksi sebagai sebuah ketukan. Hal ini karena rekaman suara pada ponsel pintar tidak memberikan getaran yang cukup untuk dibaca sebagai sebuah ketukan. Skenario ini menunjukkan agar sistem dapat mendeteksi ketukan maka diperlukan getaran, bukan hasil dari getaran tersebut yakni bunyi.

\subsection{Skenario Pengujian Ketiga}

Pada skenario pengujian ketiga dilakukan pengujian langsung dengan 15 koresponden, skenario ini untuk menguji persentase pengenalan dari sistem. Tiap koresponden memberikan nada ketukan yang berbedabeda, nada ketukan dapat berupa ketukan potongan nada lagu dengan jumlah ketukan maksimal 10. Tiap koresponden mengetuk sebanyak 10 kali. Sehingga dihasilkan 150 data yang menunjukkan tingkat pengenalan sistem. Sebelum koresponden melakukan pengujian, diberikan contoh langsung penggunaan sistem agar koresponden mengerti cara menggunakan sistem dengan benar. Data tersebut disajikan pada Tabel 5.

Tabel 5 Hasil skenario pengujian kedua

\begin{tabular}{|c|c|c|c|}
\hline $\begin{array}{l}\text { Penguji } \\
\text { ke- }\end{array}$ & Nada ketukan & $\begin{array}{l}\text { Ketukan } \\
\text { Benar }\end{array}$ & $\begin{array}{c}\text { Ketukan } \\
\text { Salah }\end{array}$ \\
\hline 1 & Shave and Haircut & 8 & 2 \\
\hline 2 & Laskar Pelangi & 8 & 2 \\
\hline 3 & Ketukan 4 kali & 9 & 1 \\
\hline 4 & $\begin{array}{l}\text { Naik-naik ke puncak } \\
\text { gunung }\end{array}$ & 9 & 1 \\
\hline 5 & Burung Kakaktua & 9 & 1 \\
\hline 6 & Ketukan 6 kali & 9 & 1 \\
\hline 7 & Tik tik bunyi hujan & 9 & 1 \\
\hline 8 & Pada hari minggu & 9 & 1 \\
\hline 9 & Cups & 8 & 2 \\
\hline 10 & Indonesia Raya & 9 & 1 \\
\hline 11 & Doraemon & 9 & 1 \\
\hline 12 & Tepuk Pramuka & 8 & 2 \\
\hline 13 & Fur Elise & 8 & 2 \\
\hline 14 & Pelangi-pelangi & 9 & 1 \\
\hline 15 & Gambang Semarang & 9 & 1 \\
\hline
\end{tabular}

Setelah seluruh koresponden menguji ketukan, maka tingkat pengenalan sistem dapat ditentukan sebagai berikut.

Persentase pengenalan $=$ (Jumlah ketukan benar/Total ketukan) x 100\%

Persentase pengenalan $=(130 / 150) \times 100 \%$

Persentase pengenalan $=87 \%$

Pada hasil pengujian yang ditunjukkan pada Tabel 5, ditunjukkan bahwa tidak ada pengujian oleh koresponden yang memberikan hasil pengujian yang benar secara keseluruhan dan hasil persentase pengenalan tidak memberikan nilai $100 \%$. Kondisi ini memberikan hasil analisis sebagai berikut.

1. Lingkungan pengujian pada saat memberikan ketukan mempengaruhi hasil identifikasi ketukan, karena getaran yang disebabkan oleh lingkungan pengujian selain ketukan yang diberikan oleh koresponden akan diidentifikasi sebagai ketukan dan mempengaruhi hasil keluaran yang didapatkan.

2. Pengujian yang dilakukan secara berlanjut oleh masing-masing koresponden selama $10 \mathrm{kali}$, mempengaruhi konsistensi jumlah ketukan, rasio waktu antar ketukan dan pelan atau kerasnya ketukan yang diberikan. Konsistensi ini lebih dipengaruhi oleh perilaku koresponden sendiri saat memberikan ketukan.

\section{PENUTUP}

\subsection{Kesimpulan}

Dari hasil pengujian dan analisis sistem pembukaan kunci automatis dengan identifikasi pola ketukan, maka dapat diambil kesimpulan sebagai berikut.

1. Sistem pembukaan kunci automatis mampu mengidentifikasi jumlah ketukan, jika jumlah ketukan yang dideteksi kurang dari atau sama dengan 10 (sepuluh), maka ketukan tersebut benar dan ketukan tersebut salah jika jumlah ketukan lebih dari sepuluh.

2. Sistem pembukaan kunci automatis mampu mengidentifikasi rasio perbandingan jarak waktu antar ketukan, jika jarak antar ketukan lebih dari 25 milidetik dan rerata jarak antar ketukan lebih dari 15 milidetik maka ketukan tersebut salah.

3. Sistem pembukaan kunci automatis mampu mengidentifikasi pelan atau kerasnya ketukan dengan mendefinisikan nilai amplitudo dengan nilai 10 untuk ketukan pelan dan 20 untuk ketukan keras yang kemudian disimpan dalam larik. Ketukan pelan memiliki nilai ambang batas bacaan analog 3-100 dan 1011023 untuk ketukan keras.

4. Suara ketukan yang direkam menggunakan perangkat ponsel pintar tidak dapat digunakan sebagai metode kontrol akses, karena suara yang direkam tidak memberikan getaran yang cukup untuk dapat diidentifikasi sebagai sebuah ketukan oleh sistem.

5. Berdasarkan hasil pengujian, kondisi lingkungan pada saat memberikan ketukan mempengaruhi hasil identifikasi ketukan yang didapatkan karena getaran tertentu yang berasal dari lingkungan pengujian, selain ketukan yang diberikan penguji mempengaruhi hasil keluaran sistem. Selain itu konsistensi koresponden dalam memberikan ketukan, juga mempengaruhi hasil ketukan

\subsection{Saran}

Berdasarkan pengujian dan analisa terhadap sistem pembukaan kunci automatis dengan identifikasi pola ketukan yang telah dibuat, sistem masih memerlukan penyempurnaan, karena itu diberikan beberapa saran sebagai berikut.

1. Perlu dilakukan penelitian lanjutan untuk mengidentifikasi jumlah ketukan yang diperlukan dan jumlah kombinasi ketukan yang dapat dihasilkan, agar sistem dapat mengenali pola ketukan yang lebih beragam dan unik.

2. Perlu dilakukan penyamaan persepsi terhadap para pengguna sistem tentang masalah pelan atau keras- 
nya ketukan yang diizinkan oleh sistem agar dikenali dengan benar. Hal tersebut dapat dilakukan dengan memberikan contoh langsung kepada calon pengguna sebelum menggunakan sistem.

\section{DAFTAR PUSTAKA}

[1] Anderson, Ross, Security Engineering, John Wiley \& Sons, Inc., Indianapolis, 2001.
[2] Atmel Corporation, Atmel 8-bit AVR Microcontroller with $2 / 4 / 8 K$

Bytes In-System Programmable Flash, Atmel, Corp., San Jose, 2013.

[3] Fitzgerland, Scott, and Shiloh, Michael, The Arduino Project Book, Arduino, LCC., Torino, 2012.

[4] Ladyada, Introducing Trinket, Adafruit, Corp., New York, 2014.

[5] Phillips, Bill, Locks and Locksmithing, McGraww-Hill, Inc., New York, 2005. 